\title{
GENOTYPIC CONTROL OF CHROMOSOME BEHAVIOUR IN RYE
}

\author{
VII. UNADAPTIVE HETEROZYGOTES
}

\author{
S. SUN and H. REES \\ Department of Agricultural Botany, University College of Wales, Aberystwyth
}

Received 21.i.64

\section{INTRODUCTION}

Ghromosome behaviour, particularly at meiosis, may vary enormously between species and, to a lesser extent, even between populations of the same species. Not uncommonly there is variation in chiasma frequency or in chiasma localisation. In outcrossing species such variation is generally assumed to be adaptive in that it determines within each population an optimum recombination, an optimum release of genetic variability. Since chiasma frequency is to a large degree genotypically controlled it is not difficult to envisage how such adaptive adjustments could arise in response to selection. In outbreeders they would depend, as for other characters, on the synthesis and the maintenance by selection of heterozygous gene combinations in relational balance (Mather, 1943). Confirmation of this view comes from the evidence on the effect of forced inbreeding on the behaviour of chromosomes. (Lamm, 1936; Müntzing and Akdik, 1948; Rees, 1955). The enforced homozygosity with the consequent disruption of relational balance results in abnormal chromosome behaviour. In such inbreeders the chiasma frequency at meiosis is almost invariably reduced, often to such an extent as to cause infertility through asynapsis. There is evidence, also, that a change in the breeding system in the reverse direction, namely towards extreme hybridity by wide outcrossing, results in equally unadaptive abnormal chromosome behaviour directly as a result of genic unbalance in these novel heterozygotes (see Rees, I96r). Subject to certain important qualifications pertaining to chromosome structural differences that affect homology, comparisons at meiosis between species and their hybrids can therefore provide information about the nature and the degree of genic divergence associated with the control of adaptive chromosome behaviour.

In the present work comparisons were made of meiosis in eleven Secale species and in hybrids obtained from six of these. In making these comparisons we have made use of the diallel cross analysis developed by Jinks (1954) and Hayman (1954), and subsequently used for heterozygous parent material, as in the present cases, by Dickinson and Jinks (1956) and by Breese (1960). This form of analysis has proved most effective. It has enabled us to describe the nature of the 
chromosome variation between the species in strictly genetic terms, i.e. of the dominance and other properties of genes controlling the variation. The analysis permits us, furthermore, to describe with some precision the genetic basis of what hitherto we should have described vaguely as genetic unbalance in the species hybrids. Finally, we have attempted to show that the chiasma frequency variation observed between species is indeed adaptive and related to their differing habits of growth.

\section{MATERIAL AND METHODS}

\section{(a) Material}

There is much confusion concerning the classification of the genus Secale (see Khush, 1962 for an admirable survey). It is variously described as comprising from five (Schiemann, 1948) to fourteen species (Roshevitz, 1947). There is disagreement

TABLE I

Brief description of the type and source of the rye populations used

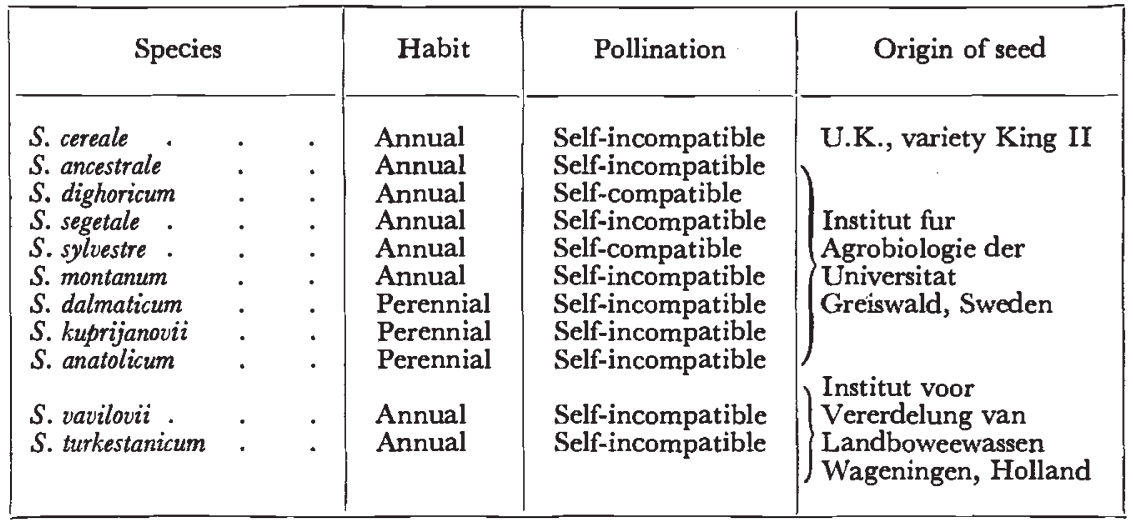

not only as to whether certain "species" merit specific rank but also a remarkable inconsistency in the descriptions given for the different species. This inconsistency applies particularly to cytological characters. For example $S$. vavilovii is described by most authors (Jain, I96o; Nürnberg-Krüger, I96o and Khush and Stebbins, I96r) as differing from $S$. cereale by two interchanges. According to others the $S$. vavilovii chromosomes are structurally similar to those of $S$. cereale (Kostoff, 1937 and Nakajima, 1955). A similar situation applies with regard to $S$. montanum ( $c f$. Khush and Stebbins, 196I and Kostoff, I937). It may be that samples from different populations within a "species" differ cytologically. More serious, it may also be that many of the rye collections, as a result of the taxonomic confusion, are misclassified. With regard to our own material the "species" listed conform morphologically to most of the descriptions available. In other respects, however, some of our "species" do not conform to recent records, especially in respect of chromosome interchanges and of "perenniality". We have for convenience retained the use of the term species for our samples but in view of the widespread uncertainty of classification within the genus, we recognise that our samples may, in some instances, represent nothing more than divergent strains or populations and that they may not, strictly, merit specific rank. A brief description of the material used in the present work appears in table I. 


\section{(b) Method}

For the diallel cross described in the following section seeds were obtained from crosses between at least three pairs of plants both within and between species. Because of the shortage of seeds, especially in some of the inter-specific crosses, the seeds including those from reciprocal crosses were bulked for each type of cross. One unfortunate consequence of the bulking of seeds is of course that we have no measure of any maternal or cytoplasmic influence on the variation. The seeds were then sown in boxes in two replicates of ro each and the seedlings transplanted to the field.

Cytological. Chiasma frequency, which was the chief character investigated was scored in twenty pollen mother cells (p.m.c.) in each plant after fixation in Carnoy's solution and staining with aceto-carmine. The chiasma frequency is expressed as the average per cell in each case.

\section{CHIASMA FREQUENCY VARIATION IN THE SPECIES AND SPECIES HYBRIDS}

The diallel cross. As was mentioned earlier the intention was to make use of the diallel cross analysis for investigating the chiasma frequency variation. We failed to incorporate all eleven species listed in table $I$ in such a cross but did complete a $6 \times 6$ diallel such as is represented in table 2 .

\section{TABLE 2}

The mean chiasma frequencies of the parent and $F_{1}$ hybrid families in the diallel cross. Data from replicates were pooled. Notation as in fig. I

\begin{tabular}{|c|c|c|c|c|c|c|}
\hline & $c$ & $a c$ & $m$ & $v$ & $d$ & $t$ \\
\hline $\begin{array}{l}c \\
a c \\
m \\
v \\
d \\
t\end{array}$ & $14 \cdot 46$ & $\begin{array}{l}12.73 \\
13.62\end{array}$ & $\begin{array}{l}12 \cdot 18 \\
13.83 \\
12 \cdot 70\end{array}$ & $\begin{array}{l}12.54 \\
13.12 \\
12.52 \\
12.86\end{array}$ & $\begin{array}{l}13 \cdot 65 \\
13 \cdot 68 \\
12 \cdot 58 \\
14 \cdot 05 \\
13 \cdot 70\end{array}$ & $\begin{array}{l}12.72 \\
12.83 \\
13.34 \\
12.53 \\
13.43 \\
14.46\end{array}$ \\
\hline
\end{tabular}

Before dealing with the chiasma frequencies, which are the main concern of the analysis, it must first be pointed out that the only interchange heterozygotes encountered were, surprisingly, restricted to some of the plants, not all, in the hybrid families vavilovii $\times$ dighoricum and vavilovii $\times$ cereale. In our own material therefore these "species" have structurally similar chromosomes except for such interchanges as "float" in populations. It is important to point out also that the chiasma frequencies of structural homozygotes and heterozygotes in these hybrid families were not significantly different from one another. There is no evidence that structural differences in this instance affect the variation in chiasma frequency. The chiasma frequencies for all plants are represented in the histograms in fig. I. In table 2 are the means for each of the parent and hybrid families from the pooled data of the two replicates. An analysis of variance of the data appears in table 3 . 
From the analysis of variance it will be seen, first, that there is no significant variation between replicates. Second, there is significant variation in mean chiasma frequencies between species $(P=<0 \cdot 00 \mathrm{I})$ and between hybrids $(P=<0 \cdot 00 \mathrm{I})$. The differences between species are of course precisely what we would expect with genotypic control and an adaptive variation in chiasma frequency. It will be observed also that the mean chiasma frequency of hybrids (1 3.05 ), when tested against the error variance, is significantly lower than that of the parents (13.63). While this test confirms a lower chiasma frequency of some of the hybrid as compared with parent families (see fig. I) it must be pointed out that the $F_{1}$ mean is not significantly lower than the parental mean when tested against the variation between hybrid and parent genotypes ( $P=0.05-0.10)$. While there is therefore some indication of lower chiasma frequencies in some of the species hybrids the hybrid

TABLE 3

The analysis of variance of chiasma frequency variation in six rye species and their hybrids

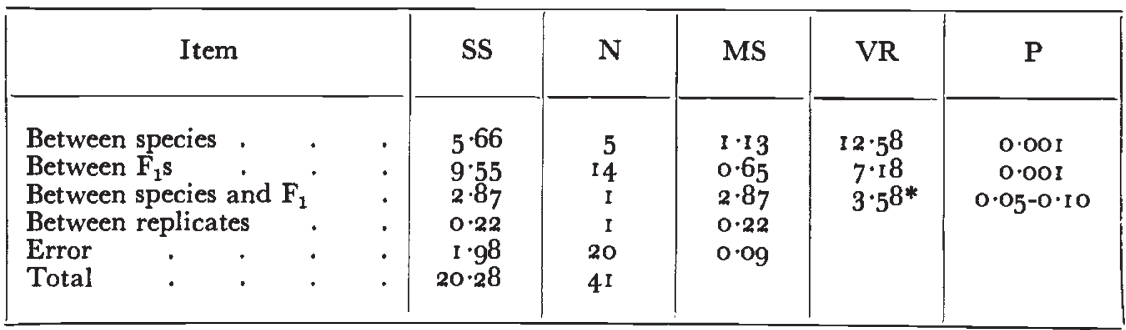

* Tested against the variation between families within parents and hybrids.

mean is not, overall, significantly lower. Indeed when we look at table 2 we note that although in the main the $F_{1}$ means are lower than the parental these are in fact two instances (montanum $\times$ ancestrale and vavilovii $\times$ dighoricum) where the $\mathrm{F}_{1}$ mean exceeds that of the parents'.

In so far as the chiasma frequencies of the parent populations are adaptive, the lower means of most $F_{1}$ hybrids may be regarded as unadaptive consequences of genic unbalance due to hybridity. One must however bear in mind also that transgression of the parental means giving an increase in chiasma frequency in hybrids may equally be regarded as a symptom of unbalance (see Rees, I $96 \mathrm{I}$ ). The diallel table as we have seen reveals both situations. Indeed of the ${ }_{5} F_{1}$ combinations to have mean frequencies lower than either parent and 2 have means higher than either parent. The probability of $\mathrm{I} 2$ of the $\mathrm{I} 5$ $\mathrm{F}_{1}$ means transgressing the parental values is, on a simple $\chi^{2}$ test, less than 0.02 . This of course is strong evidence of "overdominance", an "overdominance" operating mainly, but not entirely, to give lower chiasma frequencies in the hybrids, but in either case indicative of an unadaptive genetic unbalance of the hybrids and, it follows, of considerable genetic diversity between the species. 


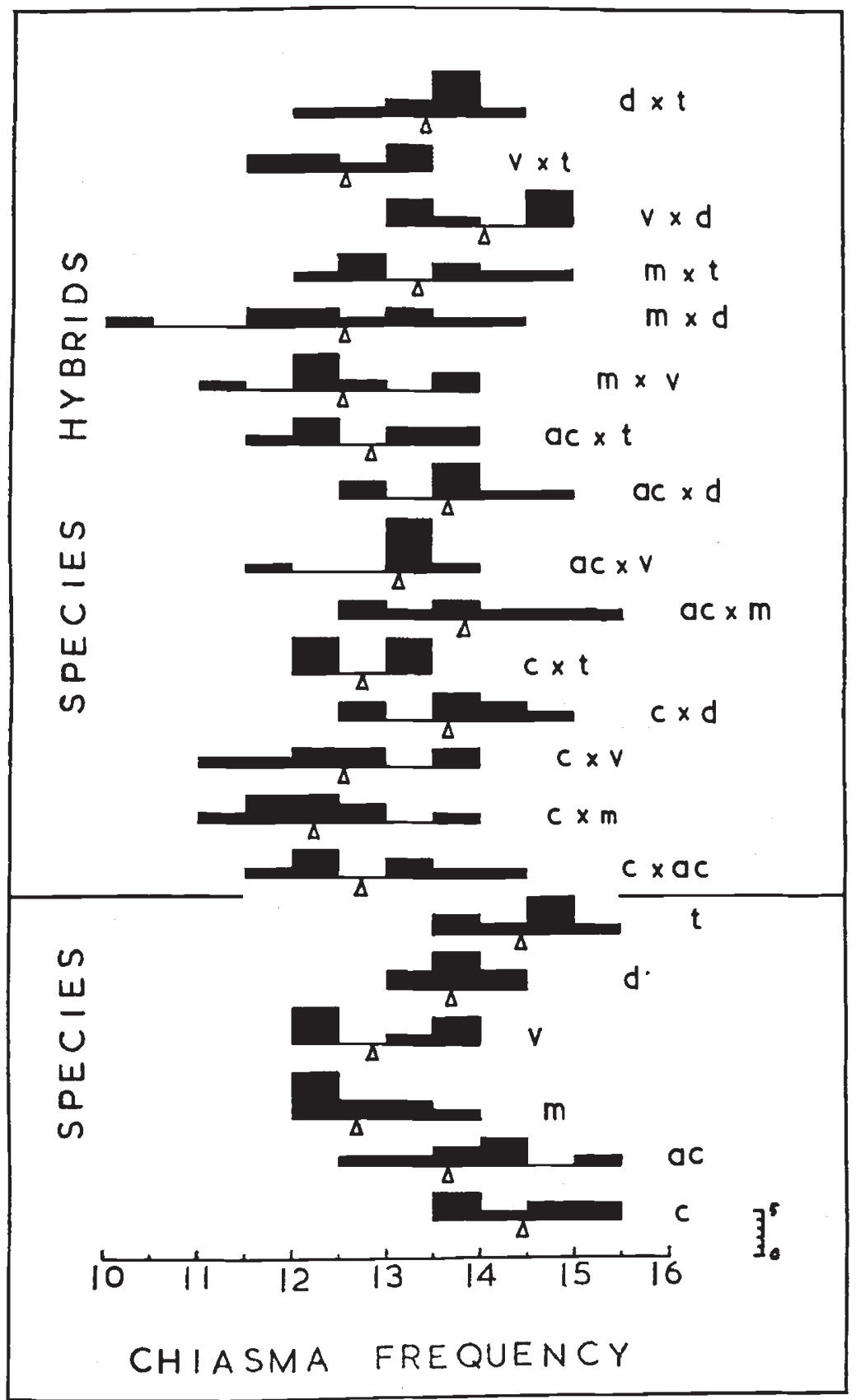

Frg. 1.-Chiasma frequency distributions in six rye species and their $F_{1}$ hybrids. $t=$ turkestanicum, $\mathrm{d}=$ dighoricum, $\mathrm{v}=$ vavilovii, $\mathrm{m}=$ montanum, ac $=$ ancestrale, $\mathrm{c}=$ cereale. Altogether $\mathrm{I} 74$ plants. 
A more detailed analysis of the data was desirable not only to confirm the evidence for "overdominance" but, also, to determine as far as possible the nature of the genetic control excercised over the chiasma frequency variation. A most convenient analysis for this purpose is the $W r / V r$ analysis of Jinks (1954) and Hayman (r954).

\section{The Wr/Vr analysis}

In fig. 2 the values of $W r$ (i.e. the covariances of the $F_{1}$ family means with the means of the non-recurrent parents) are plotted against the

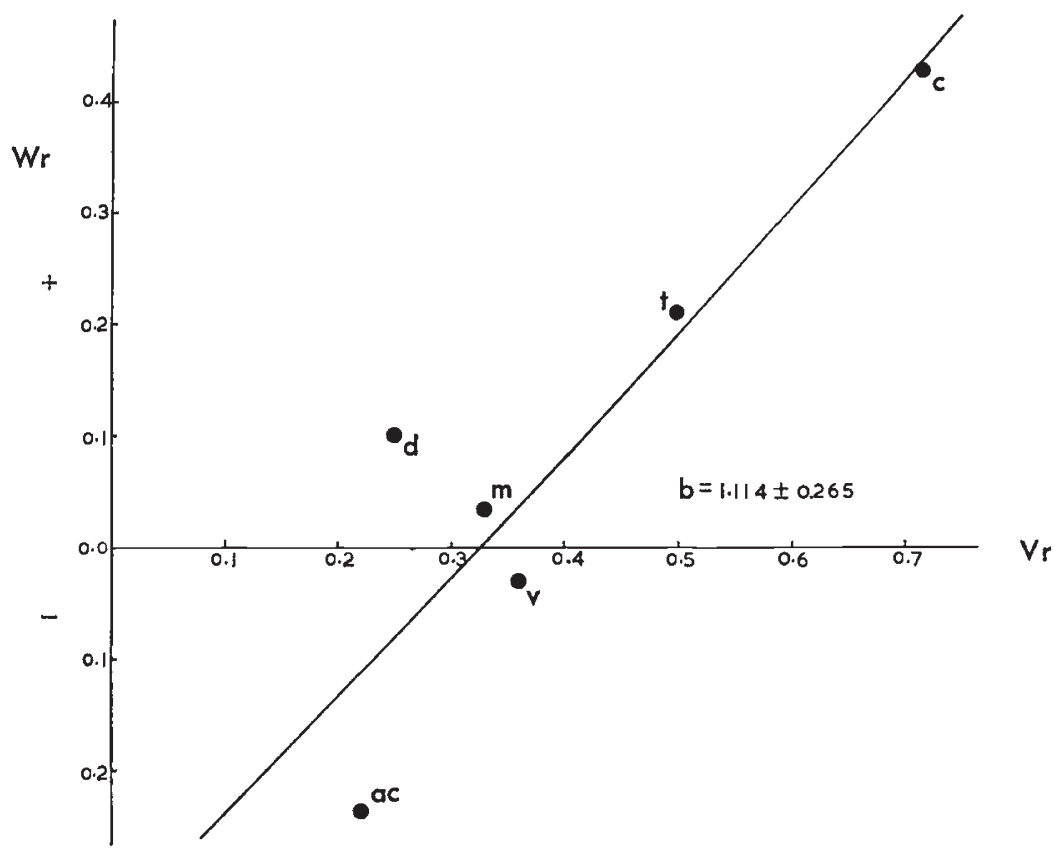

Fig. 2.-The $W r / V r$ regression from the diallel cross. Symbols as in fig. I.

$V r$ values (variances of $F_{1}$ means and their recurrent parents). As will be seen from this graph $W r$ and $V r$ are strongly correlated. A regression analysis shows that the correlation is significant $(\mathrm{P}=<0.02)$ the regression line having a slope $(b)$ of $I \cdot I_{I} 4 \pm 0 \cdot 265$. We note also from the graph that the $W r / V r$ regression line intersects the $W r$ axis below zero and a $t$-test shows the departure from zero to be significant $(t(4)=7.23, \mathbf{P}=<0.01)$.

From these observations we draw the following conclusions:-

I. There is strong evidence for "overdominance" controlling hybrid chiasma frequencies. The evidence does not come from the slope of the $W r / V r$ regression, the $b$ value being not significantly different from I, but from the fact that the regression intersects the $W r$ axis below zero. Indeed the $W r / V r$ graph is typical of that expected as a consequence of classical overdominance, i.e. of allelic gene interaction (see Jinks, 1955). 
While this evidence fully confirms the overdominance inferred earlier we must note, in passing, that the case for allelic interaction is not unequivocably established from these data. At least one other factor could produce a $W r / V r$ regression of the above kind where non-allelic as distinct from allelic gene interactions was the basis of the overdominance. This is that combinations of many genes (super-genes) within large chromosome blocks derived from the different parental species may interact in controlling the chiasma frequencies in hybrids. In this case the "alleles" would comprise combinations of genes and it follows that the interaction between "alleles" would be compounded of the interaction of many genes within them.

2. From the order of the points in the graph the order of species with most dominant genes controlling chiasma frequency is $S$. ancestrale, $S$. vavilovii, $S$. montanum, $S$. dighoricum, $S$. turkestanicum and $S$. cereale. We note too that $S$. ancestrale, the species with most dominant genes, has the lowest chiasma frequency and that $S$. cereale and $S$. turkestanicum, which carry most recessives, have the highest chiasma frequencies. It appears therefore that high chiasma frequencies within this genus depend on the action of many recessive genes.

To summarise, the analysis of mean chiasma frequencies has revealed, first, a heritable variation between the species. Second, the chiasma frequencies of hybrids between species generally transgress the parental values mainly, but not entirely, in the direction of lower chiasma frequencies. In both cases whether of "negative" or of "positive" heterosis, the transgressive hybrid values are interpreted as symptoms of genetic unbalance in the heterozygotes. The argument is that combinations of genes within species are, through natural selection, relationally balanced to maintain a presumably adaptive optimum chiasma frequency and that this balance is disrupted by relatively extreme hybridity to give transgressive chiasma frequencies in $\mathbf{F}_{1}$. The analysis described has, in addition, permitted a fairly precise description of the nature of the genetic variation between the parental populations and an explanation of the genetic basis of the unbalance in hybrids between them.

\section{CHIASMA FREQUENCY AND PERENNIALITY}

Throughout this work the assumption has been that the chiasma frequency variation between species is adaptive, that species or populations in varying circumstances maintain an optimum chiasma frequency effecting an optimum release of variability through genetic recombination. However reasonable such an assumption may be, one must admit that there is very little direct evidence from work on any organism which demonstrates the adaptive nature of such variation. Recently, however, Rees and Ahmad (1964) have shown that chiasma frequencies in Lolium are correlated with growth habit. Lolium populations which are annual in habit have higher chiasma frequencies than 


\section{TABLE 4}

The mean chiasma frequencies estimated from each of eleven rye species

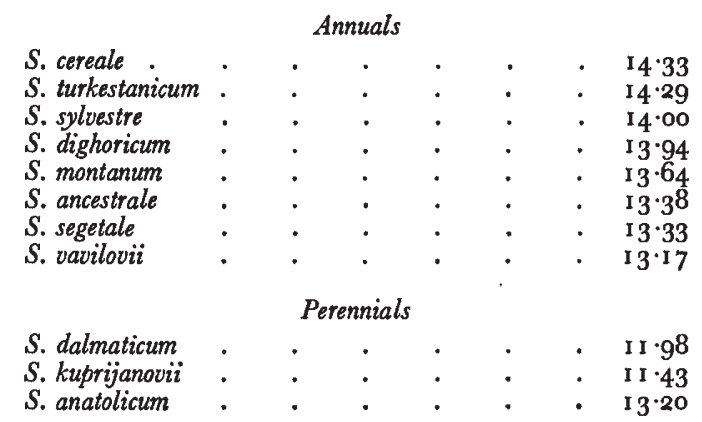

perennial populations. The conclusion drawn was that the chiasma frequency varied adaptively in relation to habit. Some rye species are perennial and others are annual and it is clearly worthwhile to determine whether a similar correlation between chiasma frequency and habit applies as in Lolium. For this purpose a separate experiment was carried

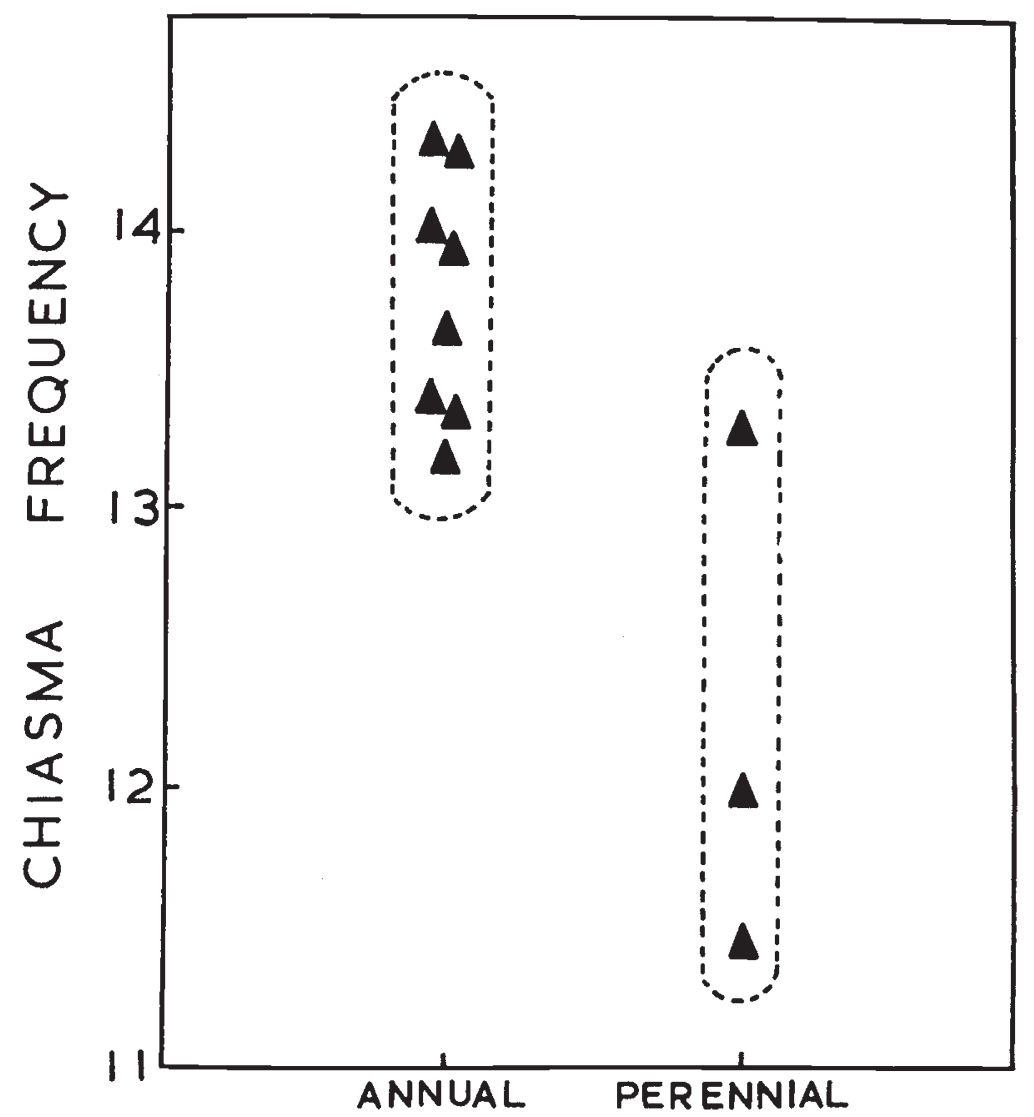

FIG. 3.-Species chiasma frequencies plotted against growth habit. 
out incorporating all the eleven species listed in table I. An average of nine plants were scored in each species and the chiasma frequencies appear in table 4 and are plotted according to growth habit in fig. 3 . It is obvious from this graph that the chiasma frequencies of annuals and perennials differ and a $t$-test confirms that the difference is significant $(\mathrm{P}=<0.02)$. As in Lolium, perennials have the lower, annuals the higher, chiasma frequencies and there is good reason, therefore, for concluding that in rye, as in Lolium, the chiasma frequency variation is adaptive and, in part at least, adjusted according to habit of growth, i.e. to the duration of the life cycle.

One cannot, of course, assume that because annual populations have higher chiasma frequencies that they are genetically more variable than the perennial. Indeed in the Lolium work referred to above the evidence indicated the reverse to be the case, that their higher chiasma frequencies compensated for a lower potential genetic variation. The same may well be true for the rye populations. For example, the only two self-compatible rye species represented, $S$. sylvestre and $S$. dighoricum, are annuals. Being largely if not entirely self-pollinating they must be genetically relatively homogenous with a low potential genetic variation. Yet both, as we see, have high chiasma frequencies.

So far as it goes, therefore, the results in rye are closely similar to those in Lolium. First the amount of genetic recombination as measured by chiasma frequency is related to habit and hence is presumed to be adaptive and, second, the high and low chiasma frequencies may compensate, respectively, for a low and high genetic potential variability.

\section{DISCUSSION}

The distribution and frequency of chiasmata at meiosis are important in two respects. First, from the standpoint of fertility they determine the extent of metaphase pairing. In diploid organisms at least one chiasma per chromosome pair is an obvious requirement for the complete bivalent formation necessary for producing fertile gametes. Adaptation to ensure such complete pairing is well established and particularly striking in species where chromosomes within the complement differ greatly in length (see Mather, I938). Second, chiasma frequency is one of the chief factors which controls, theoretically, the rate of release of genetic variability through recombination. While there is less direct evidence to confirm an adaptive variation of chiasma frequency in this latter respect there is some indication from recent work on Lolium (Rees and Ahmad, I 964), and from the present work on rye that the chiasma frequencies of populations vary adaptively according to their growth habit, to wit, the degree of perenniality.

With regard both to fertility and variability control it has long been recognised that the adaptive requirements in different populations or species may be achieved by genotypic control (Darlington, I932; see also Rees, I96I). Genetic analysis of this kind of chiasma frequency 
variation between species is, however, often difficult and sometimes impossible because other factors particularly chromosome structural variation, also influence the chiasma frequency. When, for purposes of analysis, hybrids are produced between the species the effects of structural non-homology and of genotype on the chiasma frequency in hybrids and hybrid derivatives are often confused and inseparable. Consequently, comparatively little is known of the kind of genotypic variation associated with adaptation and with speciation. The present work was an attempt to provide such information. The chromosome complements of the closely related species used differ comparatively little in structure so that analysis of chromosome behaviour in the species hybrids is more or less free of confusion between genotypic and structural causes. The use of the diallel analysis permitted, moreover, a precise and strictly genetic assessment of the divergence between the species; an assessment which accounts for the variation in terms of dominance and of interaction. This analysis allowed too for a similar genetic appraisal of the causes of the hybrid unbalance. It depended, as we saw, on the interaction of, presumably, adaptive gene systems in heterozygous combinations.

\section{SUMMARY}

I. An analysis of chiasma frequency variation in a $6 \times 6$ diallel cross between rye " species" confirms that the variation is genotypically controlled.

2. Of the $I_{5} F_{1}$ hybrid populations 12 have mean chiasma frequencies which transgress the parental values, mainly but not entirely in the direction of lower chiasma frequency. The "overdominance" in $F_{1}$ is interpreted as reflecting unadaptive genic unbalance and is shown to depend on interaction between, presumably, adaptive parental gene combinations.

3. Species with high as compared with low, chiasma frequencies show least "dominance" in the inheritance of chiasma frequency variation.

4. Evidence is presented which indicates that the chiasma frequency variation between species is adaptive in relation to the length of the life cycle. Annuals have higher chiasma frequencies than the perennials.

\section{REFERENCES}

BREESE, E. L. I96o. The genetic assessment of breeding material. Proc. 8th Intern. Grassland Congr., 45-49.

DARLINGTON, C. D. 1932. The control of the chromosomes by the genotypes and its bearing on some evolutionary problems. Amer. Nat., 96, 25.

Dickinson, A. G., AND JINKs, J. L. 1956. A generalised analysis of diallel crosses. Genetics, 4I, 65-78.

hayman, B. I. 1954. The theory and analysis of diallel crosses. Genetics, 39, 789-809. JaIN, S. x. 1960. Cytogenetics of rye (Secale spp.). Bibl. Gen., 29, I-86.

Jinks, J. L. 1954. The analysis of quantitative inheritance in a diallel cross of Nicotiana rustica varieties. Gen., 39, 767-788. 
JINKs, J. L. I955. A survey of the genetical basis of heterosis in a variety of diallel crosses. Heredity, 9, 223-238.

кнUsн, G. S. I962. Studies in Secale. II. Evol., ${ }_{1} 6,484-496$.

KhUsh, G. S., AND stebBins, L. G. I96r. Cytogenetic and evolutionary studies in Secale. I. Some new data on the ancestry of S. cereale. Am. 7. Bot., 48, 723-730. kostofF, D. 1937. Interspecific hybrids in Secale. Current Sci., 5, 583-584. LAMM, R. 1936. Cytological studies on inbred rye. Hereditas, 3I, 2 1 7-240.

MATHER, $\mathbf{x .}$ 1938. Crossing over. Biol. Revs., I3, 252.

MATHER, x. I943. Polygenic inheritance and natural selection. Biol. Revs., I8, $32-64$.

MÜNTZING, A., AND AKDIK, s. I948. Cytological disturbances in the first inbred generation of rye. Hereditas, 34, 485-509.

NAKAjIMA, G. 1955. Cytogenetical studies on the interspecific hybrids within the genus Secale. Fap. 7. Breeding, 6, I 7 I-I 74 .

NÜRNBERG-KRÜGER, U. Ig6o. Cytogenetioche Untersuchungen der Gattung Secale, L. Zeit. für pflanzenzüchtung, 44, 63-72.

REes, H. I955. Heterosis in chromosome behaviour. Proc. Roy. Soc. B., 144, I 50-1 59 .

REES, H. I96r. Genotypic control of chromosome form and behaviour. Bot. Rev., 27, 288-318.

REES, H., AND AHMAD, K. I964. Chiasma frequencies in Lolium populations. Evol. I7, 575-579.

ROSHEVITZ, R. Y. 1947. A monograph of the wild, weedy and cultivated species of rye. Acta. Inst. Bot. Nomine. Acad. Sci. U.S.S.R., Sev. I, Fl. et Syst., 6, 105-103. schiemann, e. 1948. Weizen, Roggen, Gerste, Systematik, Geschichte und Verwendung. Fischer, Jena. 